ORIGINAL ARTICLE

\title{
Measuring the quality of referral letters about patients with upper gastrointestinal symptoms
}

\author{
M Jiwa, M Coleman, R K McKinley
}

Postgrad Med J 2005;81:467-469. doi: 10.1136/pgmj.2004.027516

See end of article for authors' affiliations

....................

Correspondence to:

$\operatorname{Dr} M$ Jiwa, Doncaster and

Bassetlaw Hospitals NHS

Foundation Trust

Armthorpe Road,

Doncaster DN2 5LT, UK;

m.jiwa@sheffield.ac.uk

Submitted 3 August 2004

Accepted

10 November 2004

\begin{abstract}
Background: General practitioners state the reason for referring patients in referral letters. The paucity of information in these letters has been the source of criticism from specialist colleagues.

Objective: To invite general practitioners to set standards for referral letters to gastroenterologists and to apply these standards to actual referral letters to one specialist gastroenterology unit.

Methods: A scoring schedule was designed based on the responses to a questionnaire survey of a large sample of all general practitioners in one locality. Altogether 350 consecutive letters to a district general hospital about patients referred for an upper gastrointestinal specialist opinion were subsequently scored using the schedule.

Results: 102 practitioners responded to the survey. Their responses imply that colleagues assess and record findings on 18 potential features of upper bowel disease. In practice most referral letters address fewer than six features of upper bowel disease. The mean number of positive features of upper gastrointestinal disease reported in each letter was one.

Conclusions: This study reported a failure to meet "peer defined" standards for the content of referral letters set by colleagues in one locality. Referral letters serve many purposes, however, encouraging full documentation of specific clinical findings may serve to increase the pre-referral assessments performed in practice.
\end{abstract}

f $\mathrm{n}$ the UK the referral to secondary care still requires a letter from the general practitioner to the specialist. The letter records the general practitioner's reasons for requesting a specialist consultation or test such as endoscopy. Ideally it should incorporate sufficient information to permit those who may benefit from rapid access to specialist care or investigation, or both, to be identified. ${ }^{12}$ This may have been facilitated by the publication of national UK guidelines to help general practitioners decide which patients to refer urgently. ${ }^{3}$ Nevertheless the quality of referral letters has been and remains variable. ${ }^{4-7}$ In one survey $38 \%$ of consultants stated that they have been provided with inadequate information by general practitioners "fairly" or "very often". 8 Nevertheless, much of the criticism of general practitioners' referral letters has been from a secondary care perspective; it is not clear how well they communicate when measured by their own standards.

We now describe how we identified the key clinical features that general practitioners in one locality considered should be included in a referral letter for upper gastrointestinal investigation, and the results of a review of their referral letters using this list as review criteria.

\section{METHOD}

Potential key clinical features for inclusion in referral letters were identified by reviewing available referral guidelines and papers identified by a literature search of Medline, Ingenta, CINAHL, and the Bath University ISI database using the terms "upper gastrointestinal" (exploded) in association with "primary care", "cancer", "letter", and "guidelines". This was supplemented by hand searches of the major UK primary care journals from 1990 to 2001 and scanning the reference lists of all articles found through the above strategies and informal discussion with general practitioner colleagues.

One hundred and thirty eight general practitioners in South Yorkshire were invited to participate in a two stage questionnaire survey given at monthly intervals. ${ }^{9}$ In the first stage they were asked to refine the list of contents for an "ideal" referral letter about a patient with upper gastrointestinal symptoms, in the second they were provided with a summary of all the responses to the first and were asked to review and if necessary change their responses. Respondents were compared with non-respondents in terms of age, sex, and the list size of their practices on data held locally.

The list of key clinical features on which there was majority agreement among the general practitioners was used to produce review criteria for referral letters for patients with upper gastrointestinal presentation. This was applied to 350 consecutive free text referral letters to a local district general hospital gastrointestinal service. The service does not offer direct access to endoscopies but a specialist appointment after reviewing the referral letter.

\section{RESULTS}

One hundred and thirty eight local general practitioners were invited to participate; 120 responded $(87 \%)$ in the first stage and were invited to participate in the second stage to which 102 responded. There were no differences in the items selected by general practitioners before and after reflecting on a summary of the group opinion. The box shows the final list of items. Respondents (102) were compared with nonrespondents (36). No significant differences were noted in terms of age, sex, list size, ssingle handed status, or ethnic origins (table 1 ).

\section{Scoring referral letters}

Three hundred and fifty consecutive referrals from 105 general practitioners to one district general hospital were scored using the schedule devised. Figure l shows the number of presenting features for upper bowel disease recorded on referral letters. It can be seen that the average referral focuses on less than six aspects of the presenting features. Figure 2 shows that the mean number of positive 
Features that should be addressed in the referral letter for patients with upper gastrointestinal symptoms

- Dysphagia

- Loss of appetite

- Haematemesis

- Weight loss

- Melaena

- Upper abdominal pain

- Iron deficiency anaemia

- Jaundice

- Dyspepsia unresponsive to treatment

- Family history of upper gastrointestinal cancers

- Pernicious anaemia

- Mass on abdominal ultrasound scan

- History of peptic ulcer disease

- History of Barrett's oesophagus

- History of surgery for peptic ulcer disease

- Cervical lymphadenopathy

- Hepatomegaly

- Vomiting

features of upper gastrointestinal disease in each letter was one.

\section{DISCUSSION}

The content of referral letters has become a bone of contention between specialist and general practitioners with published papers reporting dissatisfaction at the quality of communication. ${ }^{10}$ Referral letters for upper gastrointestinal presentations analysed using these review criteria seem to contain little information.

The principal strengths of this study are that it is based on evidence based criteria validated for the general practice context by a representative sample of general practitioners and that a large sample of referral letters was reviewed. It also samples a "naive" population to which no intervention had been applied and it is likely to represent actual practice. The population surveyed is likely to represent a typical UK general practice. The weakness of this study is that although we have identified what seems to be a glaring failure of communication between primary and secondary care, we do not know whether it affects patient care. Referral letters serve a number of functions including informing the specialist

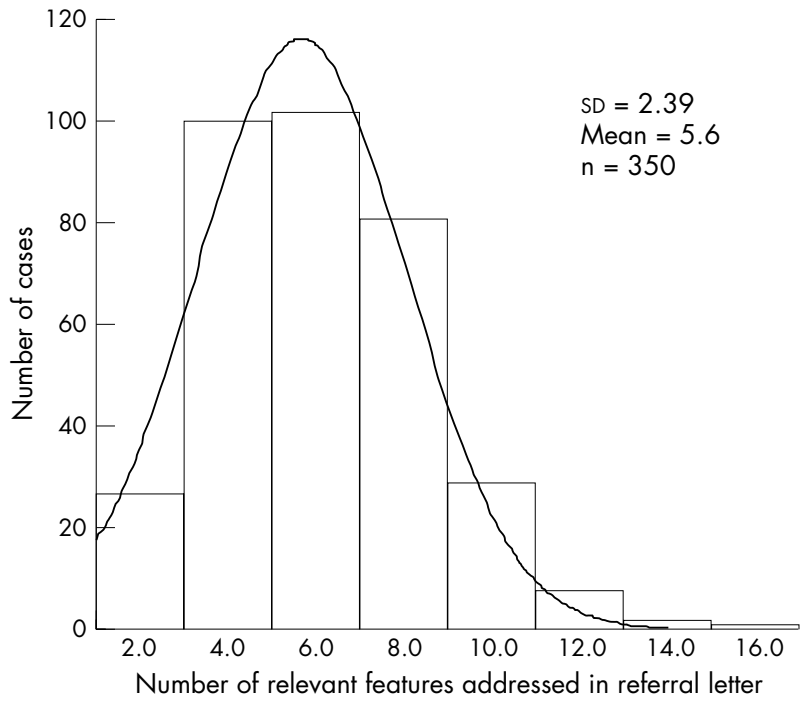

Figure 1 Distribution of the number of features of bowel disease recorded in referral letters. Maximum possible $=18$.

about the reason for the referral and as a simple request for a test or opinion. Doctors can express satisfaction with the content of referral letters even when very little information is included because they serve to facilitate a referral rather than seek to justify it. ${ }^{11}$ Patients do not always seem to come to harm when the reason for referral is not correctly interpreted from the referral letter. ${ }^{12}$ This may have been especially important to the setting of this study where patients are referred with the expectation of a diagnostic procedure being performed and all patients are seen regardless of the contents of the referral letter. The content of referral letters needs to be assessed from the perspective of the clinician engaged in a process-that is, organising a test. ${ }^{13}$

We have established that the information content of referral letters written by general practitioners is low. We do not fully understand why this is so. It may reflect that general practitioners have low referral thresholds ${ }^{14}$; that they do include all information that have about their patients' presentations in referral letters; that they do not make a full assessment of the problems with which patients have presented and have been referred; and/or that they make referral decisions using prompts not included in these referral criteria. Finally, we do not understand what their impact is on health care either at individual or population levels. Further research is needed to elucidate these problems if we are to improve communication between primary and secondary care.

Table 1 Differences between respondents and non-respondents

\begin{tabular}{|c|c|c|c|c|}
\hline & $\begin{array}{l}\text { Respondents } \\
(\mathrm{n}=102)\end{array}$ & $\begin{array}{l}\text { Non-respondents } \\
(\mathrm{n}=36)\end{array}$ & $\begin{array}{l}\text { Mean difference } \\
95 \% \mathrm{Cl}\end{array}$ & Test and $p$ value \\
\hline Age & $\begin{array}{l}47(8) \\
n=99\end{array}$ & $\begin{array}{l}49(8.6) \\
n=29\end{array}$ & $\begin{array}{l}1.85 \\
(-5.3 \text { tol } .6)\end{array}$ & $\begin{array}{l}t \text { test } \\
p=0.29\end{array}$ \\
\hline Sex & 29F: $73 M$ & 7F: $27 \mathrm{M}$ & & $\begin{array}{l}\chi^{2} \text { test } \\
p>0.1\end{array}$ \\
\hline List size & $\begin{array}{l}1997(766) \\
n=93\end{array}$ & $\begin{array}{l}2138(872) \\
n=26\end{array}$ & $\begin{array}{l}140 \\
(-488 \text { to } 206)\end{array}$ & 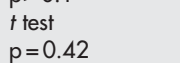 \\
\hline Single handed & 8 & 4 & & $\begin{array}{l}\text { Fisher's exact test } \\
p=1.0\end{array}$ \\
\hline \multirow[t]{2}{*}{$\begin{array}{l}\text { Ethnicity non- } \\
\text { European }\end{array}$} & $24 / 97$ & $9 / 28$ & & $\chi^{2}$ test \\
\hline & & & & $p=0.47$ \\
\hline
\end{tabular}

Data for all practitioners were not available. Figures in parentheses are standard deviations unless otherwise stated. 


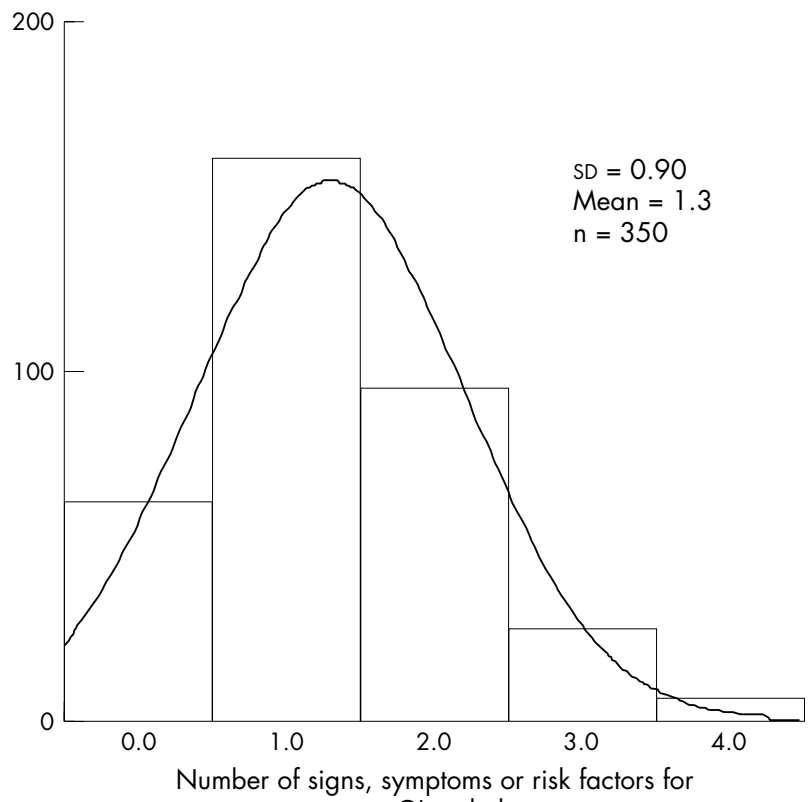

upper $\mathrm{Gl}$ pathology

Figure 2 Distribution of the number of "positive features" of bowel disease recorded in referral letters. Maximum possible $=18$.

\section{ACKNOWLEDGEMENTS}

We thank the general practitioners who participated in this survey; also the administrative team at TARGET, Doncaster for help with the project; Lindsey Shaw, Alison Wastnidge, and Jane Walker for preparing the manuscript.

\section{Authors' affiliations}

M Jiwa, Doncaster and Bassetlaw Hospitals NHS Foundation Trust, Doncaster, UK
M Coleman, Kingthorne Group Practice, Kingthorne House, Doncaster, UKR K McKinleyClinical Consultation Research and Development Unit, Department of Health Sciences, (General Practice and Primary Health Care), University of Leicester, UK

Funding: Doncaster and Bassetlaw Acute NHS Foundation Trust.

Conflicts of interest: none declared.

Ethical approval was by the chairman of the Doncaster local ethics committee.

\section{REFERENCES}

1 Heikkinen M, Pikkarainen P, Eskelinen M, et al. General practitioners' ability to diagnose dyspepsia based only on physical examination and patient history. Scand J Prim Health Care 2000;18:99-104.

2 van Bommel MJ, Numans ME, de Wit NJ, et al. Consultations and referrals for dyspepsia in general practice- a one-year database survey. Postgrad Med J 2001;77:514-18.

3 Department of Health. Referral guidelines for suspected cancer. London: Department of Health, 2000.

4 Campbell B, Vanslembroek K, Whitehead E, et al. Views of doctors on clinical correspondence: questionnaire survey and audit of content of letters. BMJ 2004;328: 1060-1.

5 Jenkin RM. Quality of general practitioners referrals to outpatient departments: assessment by specialists and a general practitioner. $\mathrm{Br} J \mathrm{Gen}$ Pract 1993;43:111-13.

6 Jiwa M, Mathers N, Walters S. The quality of referrals to colorectal surgeons: towards consensus. Curr Med Res Opin 2002;2:1-6.

7 Syed AA, Large DM. Quality of general practitioners' referral letters to diabetes secondary care. Practical Diabetes Int 2003;20:165-9.

8 Bowling A, Redfern J. The process of outpatient referral and care: the experiences and views of patients, their general practitioners, and specialists. Br J Gen Pract 2000;50:116-20.

9 Jones J, Hunter D. Consensus methods for medical and health services research. BMJ 1995;311:376-80.

10 Mead GE, Cunnington AL, Faulkner S, et al. Can general practitioner referral letters for acute medical admissions be improved? Health Bull (Edinb) 1999;57:257-61.

11 Graham PH, Wilson G. Letters from the radiation oncologist: do referring doctors give a damn? Australas Radiol 1998;42:222-4.

12 Hodge JA, Jacob A, Ford MJ, et al. Medical clinic referral letters. Do they say what they mean? Do they mean what they say? Scott Med J 1992;37:179-80.

13 Berg $M$, Goorman $E$. The contextual nature of medical information. International Journal of Medical Informatics 1999;56:51-60.

14 Little P, Dorward M, Warner G, et al. Importance of patient pressure and perceived pressure and perceived medical need for investigations, referral, and prescribing in primary care: nested observational study. BMJ 2004;328:444. 